\title{
The Centrality of (Vocational-Oriented) Knowledge Assessing Location and Configuration of Polytechnic Institutes in Portugal
}

\author{
Mafalda Toscano, Luísa Cannas da Silva ${ }^{(\mathbb{D})}$ and Teresa Valsassina Heitor * \\ CiTUA-Instituto Superior Técnico, Universidade de Lisboa, 1649-004 Lisboa, Portugal; \\ mafalda.toscano@tecnico.ulisboa.pt (M.T.); teresa.heitor@tecnico.ulisboa.pt (L.C.d.S.) \\ * Correspondence: luisacanasdasilva@tecnico.ulisboa.pt; Tel.: +351-218-418-131
}

Received: 16 July 2018; Accepted: 23 August 2018; Published: 27 August 2018

\begin{abstract}
Knowledge and creative businesses and industries have been at the core of discussions for urban renewal strategies worldwide. Educational facilities and the businesses they attract are key elements in urban dynamics, helping to promote urban diversity and contributing to enhancing the areas where they are imbedded. In Portugal, the higher education system follows a binary structure, in which institutions are divided into Universities and Polytechnics. The latter, whose mission is creating vocational-oriented knowledge, grounded on the specific needs of the regions they are in, are key regional drivers, with the possibility of becoming developers and promotors at a regional scale, affecting urban life and urban quality. This paper aims at exploring the location of polytechnic institutions within their hosting cities, attempting to understand location patterns and similarities among different institutions, as well as envisaging the impact of such a location in the engagement with the hosting city. The research is developed at two scales: the first (a) focuses on the location of the institution in its hosting city, while the second (b) focuses on the relative deepness of the internal spaces of the institution. This research aims at providing a methodology for general characterization of regionally oriented higher education institutions in terms of their location within urban systems, as well as exploring the spatial organization of the interior of the institutions analyzed.
\end{abstract}

Keywords: polytechnic institutions; urban integration; spatial organization; higher education infrastructure

\section{Introduction}

In the late 1950s, Higher Education (HE) began expanding, giving rise to a process later known as "massification" [1]. Growth in student numbers was not at first accompanied by democratization and modernization of HE, except in a very particular sense, namely, the opening up of access to a wider social spectrum. This was certainly the explicit aim of education policy, but it did not entail immediate changes in the internal structure and governance of universities. HE became more diversified and more complex, regarding its formal structure, increasingly differentiated and segmented, much as the background of those entering it.

New and different types of HE institutions were set up. Different fields of teaching and research emerged which, in turn, drew in more and different types of students: more first-generation students, older students, mostly employed, and those entering HE on the basis of skills acquired in the labor market [2].

Globally, initiatives such as the Bologna Process and comparable processes, implied a global simultaneous uniformization, affecting higher education by impacting not only on student enrolment and mobility of students, academics, and staff, but also in educational policies, and pedagogic methods and strategies. 
Beside the fact that higher education institutions (HEi) have been in the core of change and development-economic, social, inter-alia-their role within the urban context has changed in order to respond to the third strand of the university mission-that of civic engagement. Higher education institutions are a key element in urban dynamics and policies and they are progressively more included in strategic plans and development actions worldwide. In this global context, where knowledge has assumed a preponderant development role at multiple levels, the perceived impact of HEi has changed. Their social responsibility and influence on society at large has greatly increased and a third strand of university mission has risen, adding the need for universities to engage with communities and share the knowledge produced outside of the "ivory tower", with a positive effect on the transfer and exchange of knowledge among institutions, whether HEi, businesses or the wider community [3].

Therefore, it has become significant to understand the extent of the institutions' integration within urban territories, for this integration enhances the institutions' capacity of fostering connections with its adjacent territories, since evidence suggests that the spatial structure of academic premises and precincts affects the "flow of technology" [4] as is advocated by studies within the space syntax field [5-8].

The current Portuguese HE system is characterized by its dimension, complexity, and territorial dispersion. Despite showing a higher concentration in the main metropolitan areas, HE is also located all over the country in medium-sized cities and small centers in more peripheral areas [9]. Most infrastructures need modernization at both the precinct and the building level: they mainly perform as autonomous entities, causing the isolation of academic communities and are predominantly based on conventional academic spaces built according to a "one size fits all' model. However, the Campus University, conceived to provide a total environment for learning and intellectual activities, including all necessary and desirable facilities, utopian and separated from worldly matters ([10], p. 49) never took a firm hold in Portugal. Even though the first campi were built from the 1930s onwards, it was only in the aftermath of the 1974 Revolution that university premises and facilities developed at a larger scale. Despite the fact that Portugal never experienced "a Golden Age of the University Campus" [11] the University still shows "a very strong sense of place" [12].

It is expected that Higher Education institutions in Portugal will continue to transform and evolve, despite the diverse offer in terms of types higher education institutions [9,13-15]. This diversity is perceived by policy-makers as a strong asset, since it allows for a comprehensive response when it comes to meet the needs of a diverse range of learners, and of complex knowledge societies ([16] p. 34) and [17].

This diversity is greatly heightened by its organizational system, grounded in a binary structure, that differentiates universities from polytechnic institutions. Polytechnic institutions differ from universities in terms of mission, focus, and formative offer. Their focus is mostly regional, and often what they offer in terms of courses and study fields is directly related to the regional economies of the areas they are in (Figure 1). According to Portuguese legislation, "polytechnic institutions are high level institutions oriented towards the creation, transmission, and diffusion of professional type culture and knowledge, through the articulation of teaching, learning and oriented research and experimental development" [18], and "should focus in vocational training and advanced technical development, professionally oriented" [18].

This binary structure greatly contributes for the diversification that exists in Portuguese higher education, which is visible both in terms of the student body, the formative offer, and the institutional profiles, particularly as polytechnic institutions have a very large representation in terms of enrolment, hosting about $34 \%$ (academic year of 2015/2016) of the total number of students [19]. Besides, polytechnic institutions have a very large potential to fulfil the third strand mission of higher education, for their proximity to regional contexts and professional-oriented vocation. 


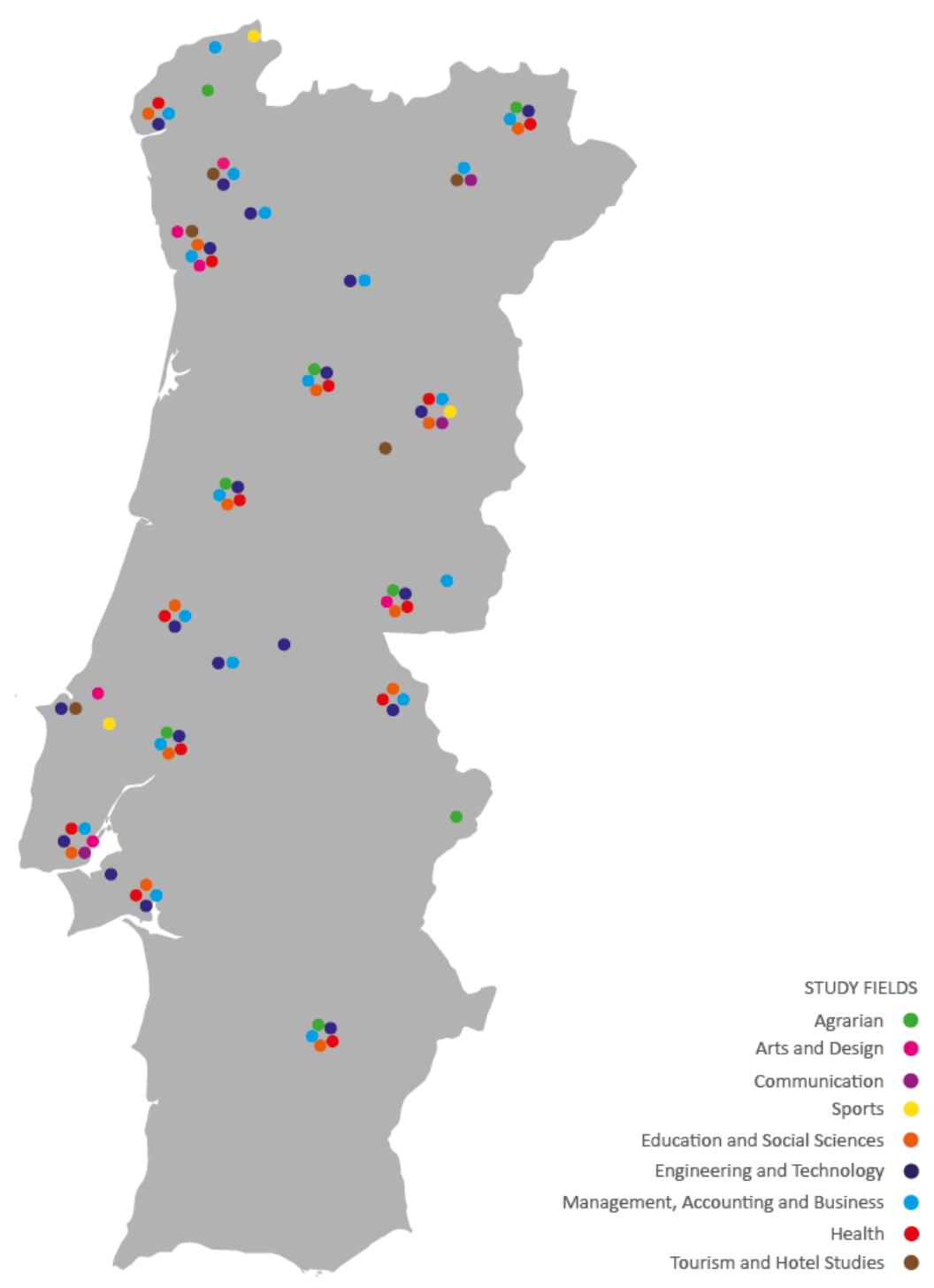

Figure 1. Polytechnic institutions geographic dispersion in mainland Portugal.

For these reasons, it matters to understand how these institutions relate with their urban territories, particularly considering their proximity relations.

This paper focuses on the impact of these relations, on an attempt to understand the ways higher education institutions can relate to their hosting cities, from a morphological point of view. It is aimed at exploring the location of polytechnic institutes within their hosting cities, identifying correspondences and patterns in different institutions, and considering the potential impact of these locations in the engagement with the hosting city. Its main goal is to contribute with an analysis framework for higher education infrastructures within urban fabrics, understanding the different types of urban insertion and connections established with local and regional players. It is included in a broad study of the morphological characteristics of higher education institutions in Portugal $[20,21]$ and aims at providing a quantitative, and thus comparable and highly replicable, tool to assess university premises, that can be used within more comprehensive studies and applied to different contexts than higher education that require the analysis of complex buildings and precincts.

\section{Methodology}

This paper is based on an exploratory methodology to assess the centrality features of higher education institutions. It is tested through its application to the analysis of two case studies: 
the Polytechnic Institute of Beja and the Polytechnic Institute of Bragança, presenting direct comparisons of schools that cover the same field, namely the Agrarian Schools and Health Schools of both institutions. However, it is intended for a broad application.

The role of higher education institutions in urban dynamics has progressively become more complex, affecting directly all users (academia and non-academia), and reaching all spheres of society. Merely their physical presence is already an element of change. Knowledge related activities impact their vicinity and wider communities to the mutual benefit of both [22,23], interfering in the process of urban development, in parameters such as employment, housing, mobility, leisure and consumer activities [24]. As central elements in a knowledge economy, higher education institutions also contribute to urban regeneration even generating processes such as studentification. Today's idea of a university shows an entrepreneurial entity, able to actively contribute for the social fabric and engaging in social, economic and cultural challenges [25], assuming the importance of the third strand of its mission-that of civic engagement $[26,27]$.

University engagement in successful urban dynamics, including its topological and functional integration, can be a key factor for attaining a sustainable urban environment. In fact, in the current context, where knowledge-based activities are seen as key drivers for economic growth, university impact within societies has achieved levels never before observed.

Also, research suggests the strongest potential of urban areas to attract knowledge workers [28]. It is crucial that urban territories rise to the expectations of knowledge workers, merging four different structures: university, research and innovation, economy, and territory [29]. Thus, the surrounding environment can also be a key factor in the success of an academic institution, for the ability it has to attract and retain knowledge workers. This dual relationship highlights the importance of dialogue between knowledge institutions and cities, on an attempt to allow an interconnected growth and development, since institutions and their hosting cities tend to become more and more co-dependent.

The research is developed at two scales: the first (a) focuses on the location of the institution in its hosting city, while the second (b) focuses on the depth of the spaces within the premises of the institution.

For the first stage, space syntax techniques [30-33] are used. Space syntax theory aims at understanding the performance of built environments [31] and their ability for hosting human activities and functions by relating social variables to built environments, through a precise method of description. It relies on the premise that space has social implications and affects users' behaviors and the possibility to shape interactions, since the system structure of space in which various activities occur can influence movement, encounter, and avoidance, as well as generates social relations [30]. According to the theory, built spaces (ranging from buildings to cities) are defined as configurations, i.e., elements in a relational environment, evaluated according to the relationships they establish. A configurational relation is described as a "relation insofar as it is affected by the simultaneous co-presence of at least a third element, and possibly all other elements, in a complex" ([34], p. 71).

Space Syntax provides a method to describe space by means of a measurable, non-arbitrary and reproducible representation [35]. The understanding of morphological structures, the quantification and modelling of configurational properties and the comparison between different spatial systems constitute its main purposes. It considers space in terms of abstract properties of topological nature rather than in terms of geometric measures. Thus, spatial layouts are described regarding the pattern of connections between spaces and the extent to which each space is directly connected to other spaces, i.e., how far each element is from all others, according to a specified measure of distance, and how many paths run through each element ([36], p. 39).

The cities are represented through a segment map [37,38], that operates as a base map for the analysis. The segment map is a development of the fewest line map (axial map) defined by space syntax theory that considers that the segments between intersections as elements in themselves, in opposition to axial lines, which are continuity lines. 
This map, while providing sufficient geographic information to allow for a clear identification of the precincts' location, performs as base map for angular analysis [39,40].

In this analysis, two main variables are chosen in order to better understand the institutions location within the urban territory-closeness centrality, accessed through normalized angular integration, and betweenness centrality, accessed through normalized angular choice [41].

Closeness centrality-integration represents the distance from each object in the system (each axial line) to all the others, characterizing the relationships among lines according to the number of changes in direction from each element to all the other within the system. This analysis evaluates each visual segment from more segregated (located deeper in the system, i.e., needing more changes in direction in order to be reached from all other locations) to more integrated, i.e., reached within fewest changes in direction.

Betweenness centrality-choice, measures the "quantity of movement that passes through each spatial element on shortest or simplest trips between all pairs of spatial elements in a system" [41]. Thus, integration-closeness represents the "to-movement potential of a space", while choice-betweenness represents the "through-movement potential" [41].

Other studies [7,42-44], have used similar approaches to relate urban morphology and location of educational facilities at the city scale. These studies demonstrate that the use of Space syntax tools allows to isolate some of the variables usually present in studies whose object is equally complex.

The second scale of analysis-the micro scale-focus on the services the institution has the potential to offer to its hosting community, through the spaces that can be used by the non-academic community, in order to access the institution's third mission potential. These spaces are evaluated according to their deepness within the institution's buildings, through justified graphs. The justified graph represents complex spatial relations in a legible manner. It is built from a root space-depth 0 - from where all other spaces are organized. All spaces connected to the root-depth 1-are aligned above it, and connect to a third level-depth 2. The graph covers all spaces within a system. The graph can be designed from any root space, changing its shape, thus reinforcing that the spatial layout changes when it is observed or perceived from a different point. Spaces are assessed in terms of their relationship to all other spaces, more than in terms of their physical characteristics. In this analysis, the root space is an exterior space from which all building entrances are accessible. The definition of an exterior root space is grounded on the premise that, according to a specific purpose of need, any user can choose the preferable (possibly, the closest) building entrance. This methodology has shown some interesting results for measuring spatial capacities in buildings [8], as wells as comparing buildings after functional changes [45].

This methodology allows to infer on the easiness to access each space of the institutions, and to extrapolate on their perceived importance through the configuration of the physical spaces. It also informs on the levels of spatial control present at each building, which are connected to the hierarchical structure of the institution itself. In the current context, in which knowledge transfer and diffusion are a part of HEi's mission, this methodology presents a tool for assessing the spatial deepness of the institution, in order to assess whether or not the physical space has the capacity for responding and expressing the institution's aims.

This paper does not intend to cover all the variables related to the morphology of higher education institutions. However, for the difficulty in isolating variables when it comes to complex institutions, the followed methodology provides enough measurable information to allow for direct comparisons. It enables us to establish a non-arbitrary and objective assessment, which provides values that are directly comparable.

\section{Case Studies}

Beja and Bragança were chosen as case studies for their local and regional importance, as cities hosting polytechnic institutions at the most southern and northern locations, respectively, within the mainland territory of Portugal, and also for their similarities in terms of formative offer. 
Both institutions present similar characteristics, being considered inner precincts in terms of their genotypical features [20,21].

These precincts are incorporated in the urban fabric, in a more or less central and prominent location, nevertheless distinguishing itself from it, presenting a distinctive character from the surrounding environment. Usually this distinction is made through urban and architectural elements, which tend to present disruptive features.

These precincts tend to be highly accessible and identifiable, assuming prominent positions within the urban fabric. Regularly their boundaries are permeable, making them inviting elements for the exterior community. Besides, the fact that they host most of the functions related to the presence of people allow them to host connections between campus users and the outside community, as long as the promoted activities are open to the public in general. Some institutions have established positive and profitable partnerships with the municipality they are located at for allowing the general public to use its facilities for a diverse range of activities [46].

These precincts adjust to the morphological features of the adjacent urban fabric, either by mimicking the scale, pursuing the same visual continuities or any other urban trait, while differencing themselves from the surrounding environment and establish a clear precinct demarcation. Regardless, their location impacts on their morphology, establishing connecting nodes with the adjacencies.

Both precincts were also created in the aftermath of the 1974 Revolution, in a period in which higher education expanded rapidly. This expansion was crucial for the development of interior regions. In the context of these cities, polytechnic institutions have highly contributed for local and regional development, being these institutions very important employers in their respective cities, and strong development promoters.

Beja nowadays hosts about 23,500 inhabitants, spread in approximately $7 \mathrm{sq} . \mathrm{km}$. The Polytechnic Institute has been there since 1979, when the Agrarian and Education Schools were created. In 1991 the formative offer of the institution was complemented with the creation of the Technology and Management School, and finally, the Health School was created in 2002.

Bragança hosts around 24,000 inhabitants, spread within the approximately $10 \mathrm{sq} . \mathrm{km}$ that compose the area of the city. The Polytechnic Institute was created in 1983 and is nowadays composed of four schools located in Bragança-Agrarian, Technology and Management, Education, and Health-and one school located in Mirandela, about $60 \mathrm{~km}$ from Bragança, the School of Communication, Administration, and Tourism.

Within the Portuguese context, not only do these precincts belong to the same category in terms of morphological traits, but they also present similar hierarchical structure and formative offer, while having a similar profile in terms of regional engagement.

\section{Macro Scale-Segment Analysis}

The two cities present very different urban fabric structures, which is highlighted by their segment map configurations. Beja's urban fabric shows a grid overlaying a radial structure (Figure 2a). Bragança, on the other hand, presents an organic layout (Figure 2b). Bragança shows more than twice the number of axial lines than Beja, and about 1.7 times the number of segment lines. This demonstrates that, besides its larger size, its structure is also more fragmented than the one of Beja, a fact that is underlined by a lower ratio between axial and segment lines. This fact is also verified by comparing the average line length, of $143 \mathrm{~m}$ in Bragança (where maximum line length is roughly $1400 \mathrm{~m}$ ), and of $160 \mathrm{~m}$ in Beja (where maximum line length is about $2000 \mathrm{~m}$ ). 


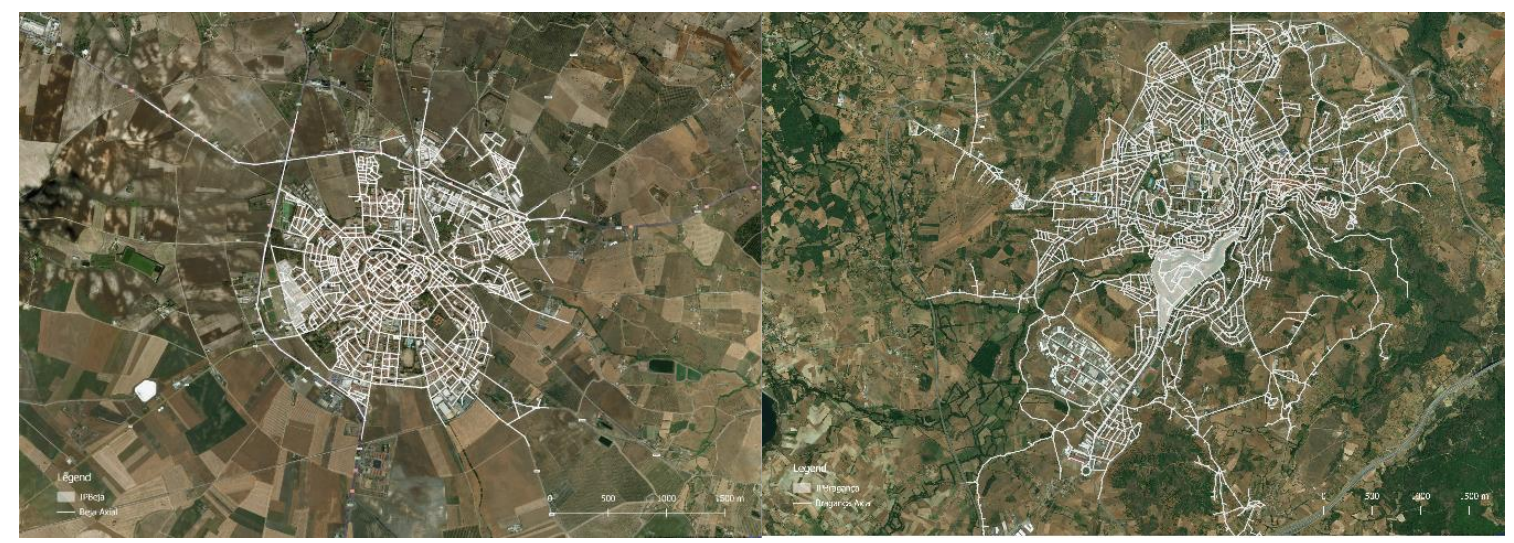

(a)

(b)

Figure 2. Axial maps: (a) Beja; (b) Bragança.

These structural features of the cities justify the fact that Bragança presents lower values for normalized angular integration (NAIN) than those observed in Beja, despite its larger size and higher number of both axial and segment lines. In terms of normalized angular choice (NACH) both cities present a similar behavior. The locations of the Polytechnic Institutes differ in both cities. Despite the fact that both precincts are considered inner precincts $[20,21]$ there are some differences between them. In Beja, the precinct is located at the edge of the urban fabric, but still included within the city's external ring. In Bragança, the precinct is located within the fabric, in relatively central position in geographical terms. However, despite the geographic location within the cities' respective boundaries, in terms of topological centrality, the results are very different.

In Beja, the integration core overlaps with the central ring (Figure 3a), which demonstrates the importance of the radial structure of the city. The Polytechnic schools are grounded on the exterior ring, but still connected to the integration core, for the small dimensions of the city.

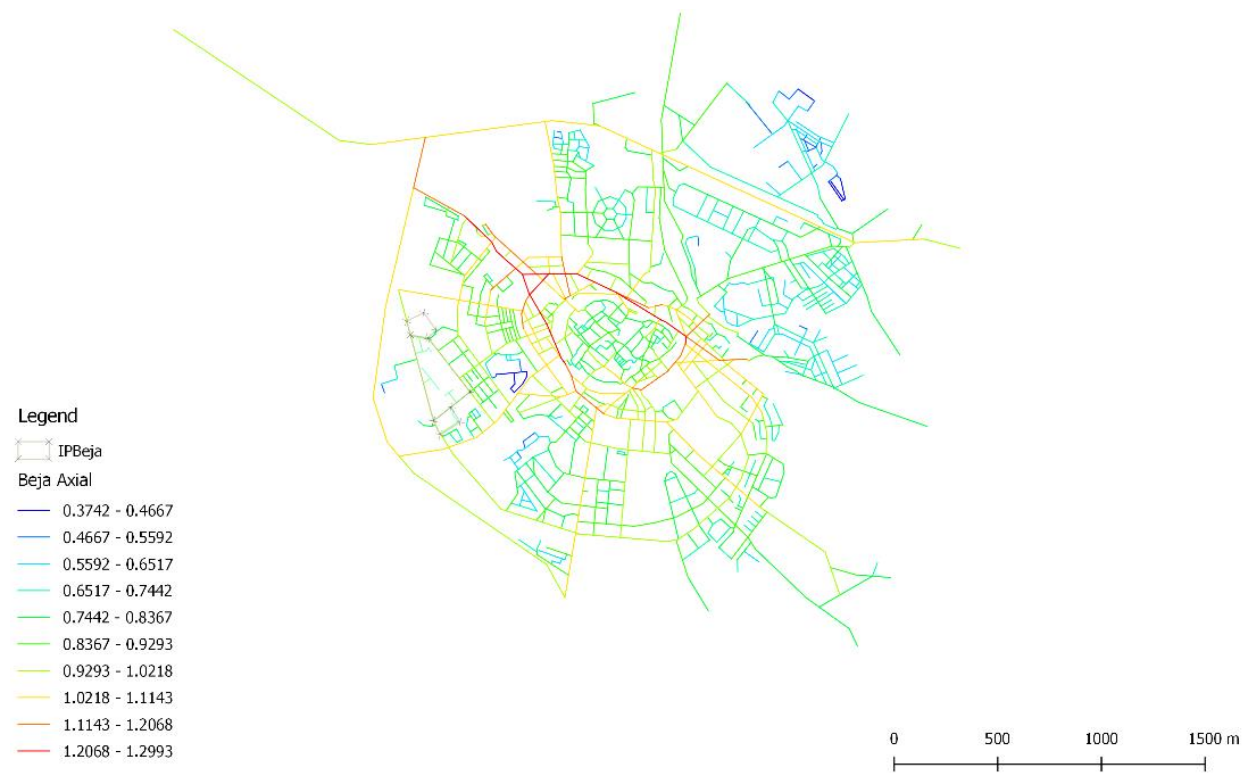

(a)

Figure 3. Cont. 


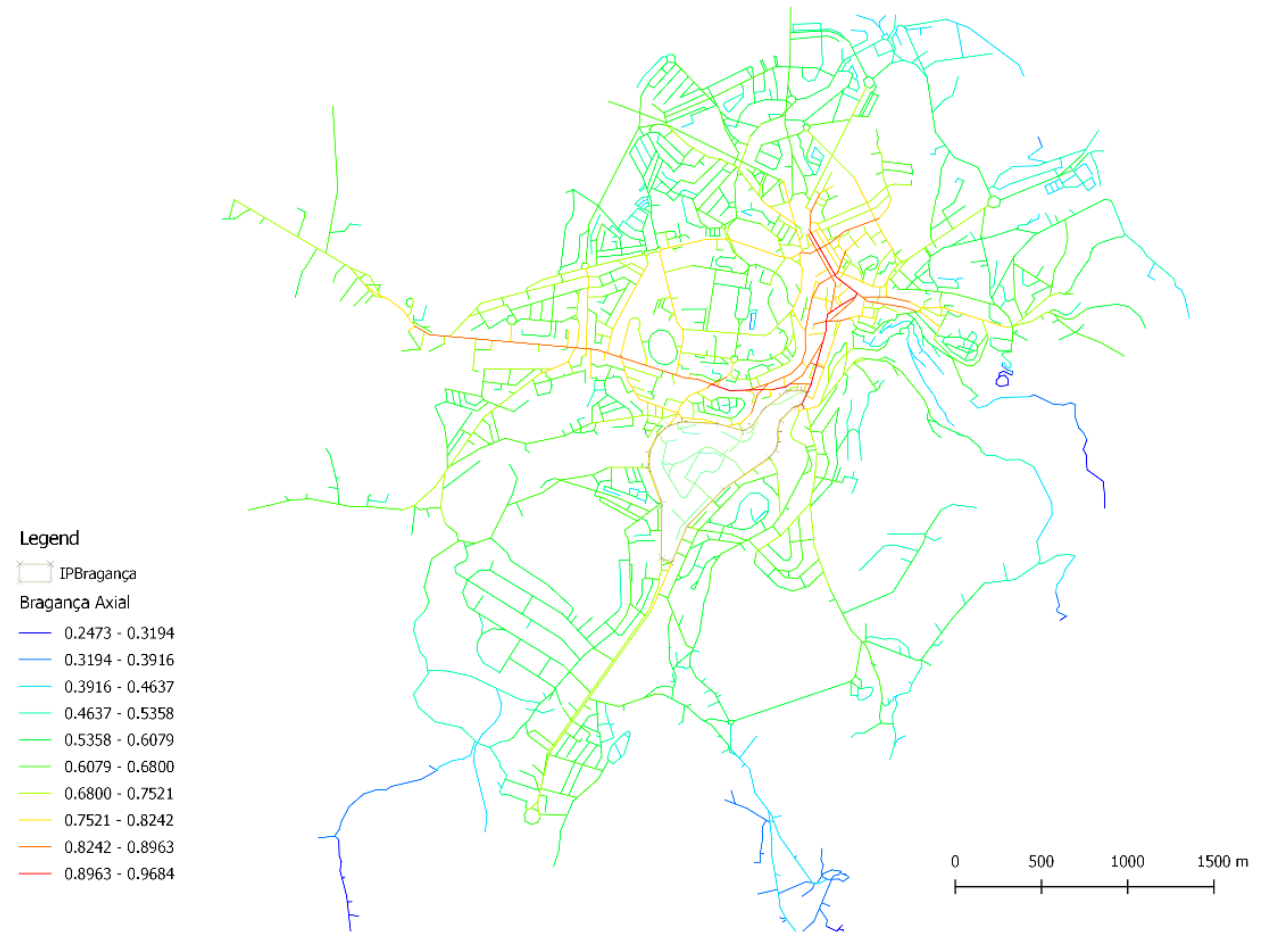

(b)

Figure 3. Segment maps—normalized angular integration (NAIN) Rn: (a) Beja; (b) Bragança.

In Bragança, the integration core presents a more fragmented structure, grounded on the topography of the city (Figure 3b). The polytechnic, is located in close proximity, south from it.

As such, in both cases, the polytechnic institution, does not have the potential to constitute a destination in terms of to-movement in random travels, as far as the system configuration is concerned.

When comparing the urban fabric within the precinct's boundaries, analyzed through the values presented by the segment lines that are inscribed within the precinct, we observe slightly higher values of average NAIN in both cases when referenced to the same variable at the city scale. Similarly, in both precincts the main access to the precinct-considering the street in which the main entrance is located-shows a NAIN value above the average of the city, and also slightly above the average of the precinct.

The analysis of NACH highlights that the foreground network [47] of Beja is the radial structure that defines the city (Figure 4a). The precinct is located in close proximity with this structure, however being in itself composed and part of the background network of the city (Figure 4b).

A similar situation occurs in Bragança, where the foreground network is more fragmented and organic, but still grounds the polytechnic schools, whose fabric is also part of the background network.

Considering the through-movement potential, the Polytechnic Institute of Beja presents a better behavior than its homonym in Bragança, due to higher value of NACH of its main access, which is located in a street segment that has the potential to be highly used in random travels through the city.

Bragança shows lower minimum, average and maximum values of NAIN. The assessment of $\mathrm{NACH}$ shows the cities present very close maximum values, and also similar average values, that fit into the reference values obtained by Hillier, Yang, and Turner [41]. 


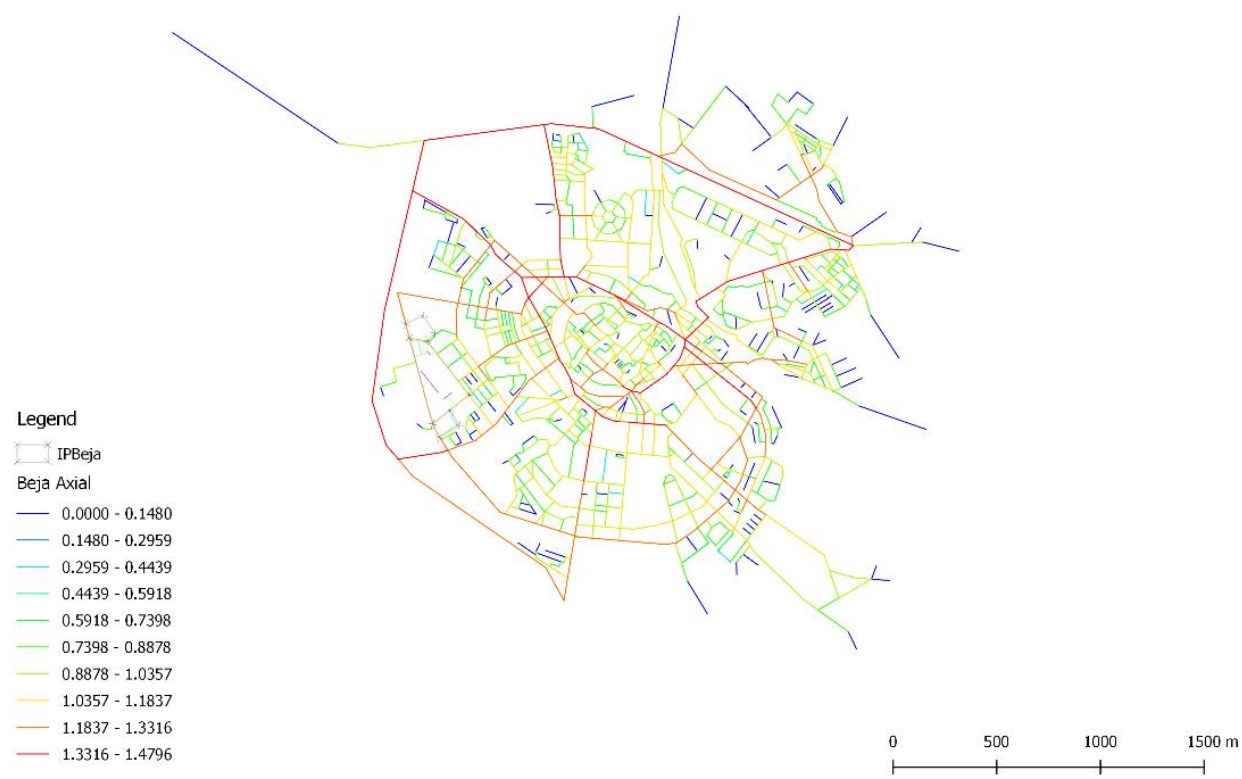

(a)
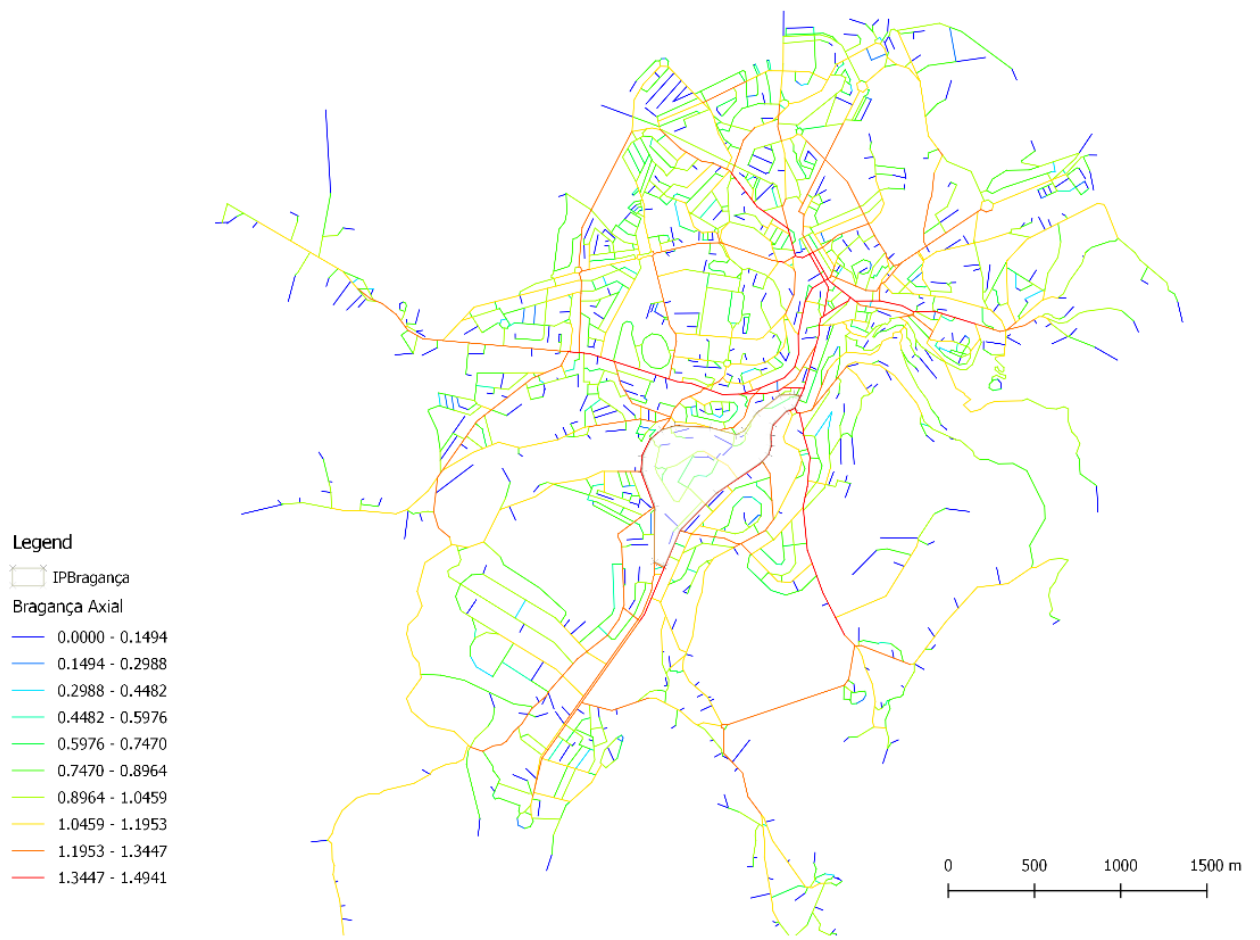

(b)

Figure 4. Segment maps—normalized angular choice (NACH) Rn: (a) Beja; (b) Bragança.

\section{Micro Scale-Functional Analysis}

In order to complement the macro scale analysis, two schools of each institution were assessed in terms of functional and spatial organization (Figure 5). 


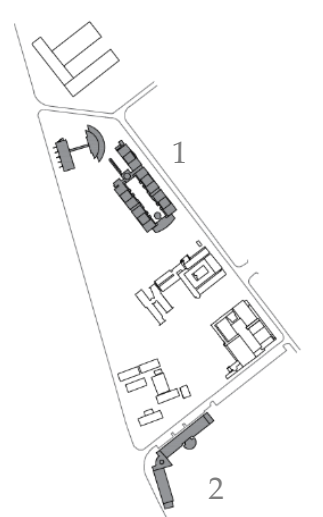

(a)

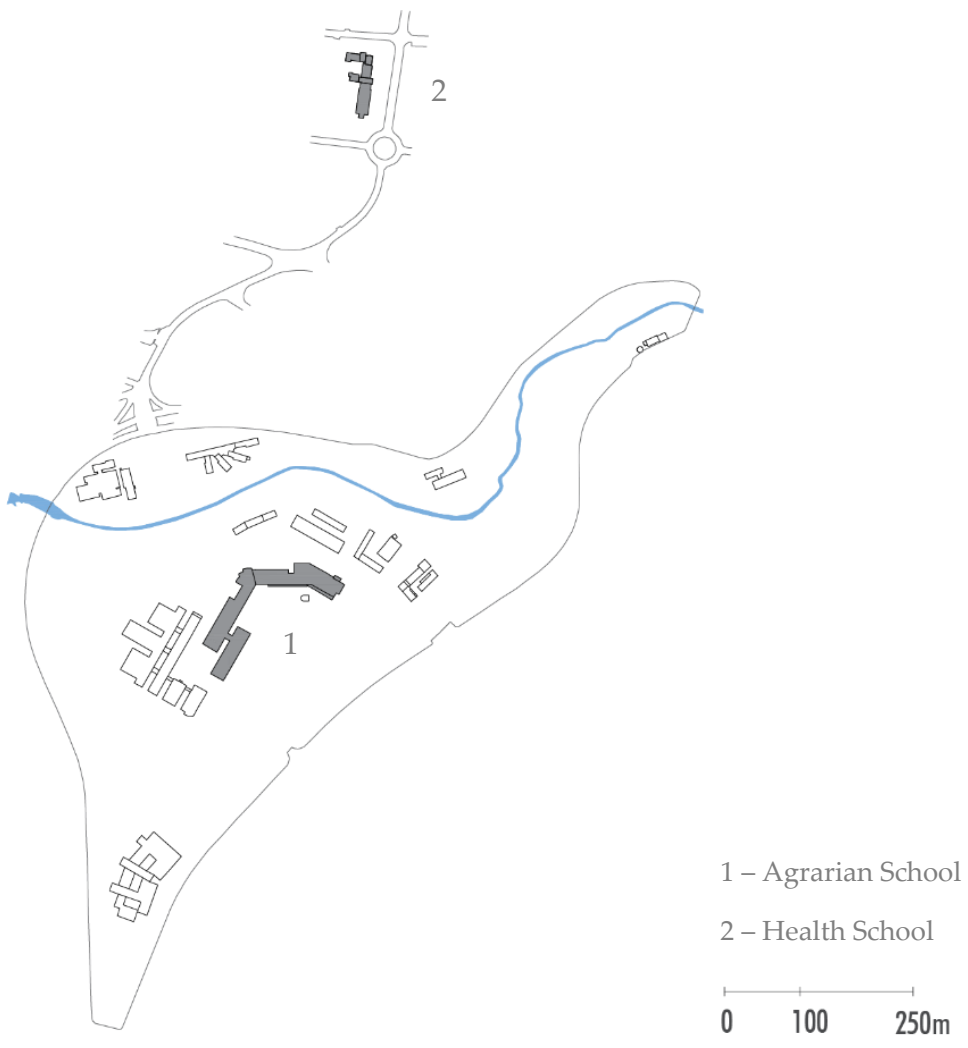

(b)

Figure 5. Precincts of the Polytechnics Institutes: (a) Beja; (b) Bragança.

Justified graphs (V-E) were made for each school, based on the plans provided by the respective polytechnics, identifying the links between the different spaces (Figure 6). These aim at providing a general characterization of the organization layouts of each school, as well as to identify the levels of deepness of different functional spaces. In the scope of this paper and attempting to scope the potential level of community engagement in Polytechnic institutions, the focus is placed upon the spaces whose functional offer can be shared with the community, rather than on exclusively academic areas. The following categories were used for the classification of areas: learning spaces, research spaces, administrative spaces, technical areas, circulation areas, accesses, areas with exterior access, auditorium, library and café. From these, auditoriums, libraries and cafes were highlighted as the ones that were more prone to promote diversification of users, social interactions, and contribute more towards community engagement.

In each graph, a general exterior point of access was considered, from which all building entrances are connected. This places all entrances at the same accessibility level, assuming each user chooses the entrance nearest to the spaces he wants to reach. Access between floors (vertical circulation) was represented with curved lines, to differentiate them from other links. Each accessibility level corresponds to the number of spaces one must go through in order to reach a destination.

The Agrarian School of Beja is divided into two independent buildings: one that houses the administrative spaces, research spaces, classrooms, laboratories and café; and another housing the auditorium, classrooms and laboratories. 
Agrarian School - Polytechnic Institute of Beja

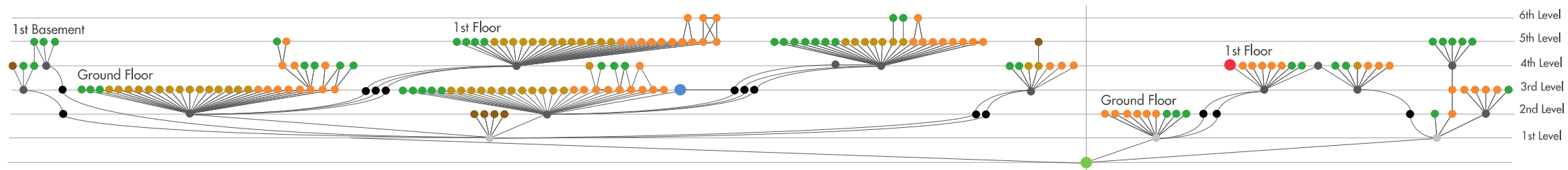

Agrarian School - Polytechnic Institute of Bragança

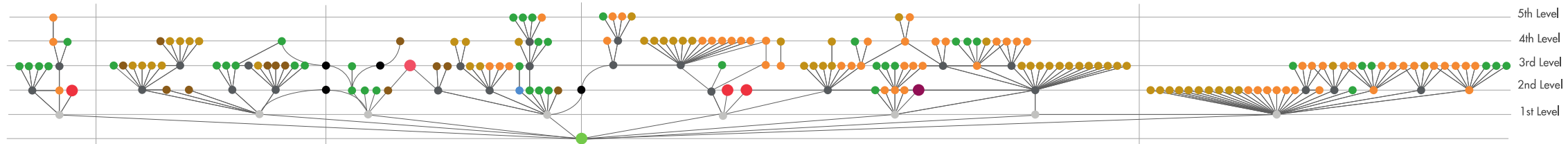

Health School - Polytechnic Institute of Beja

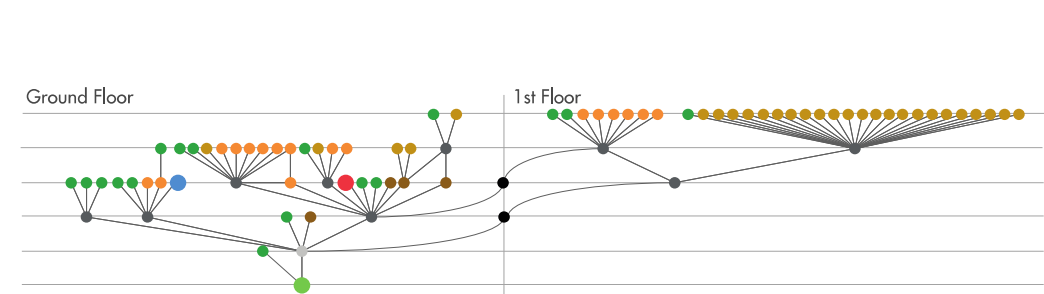

Health School - Polytechnic Institute of Bragança

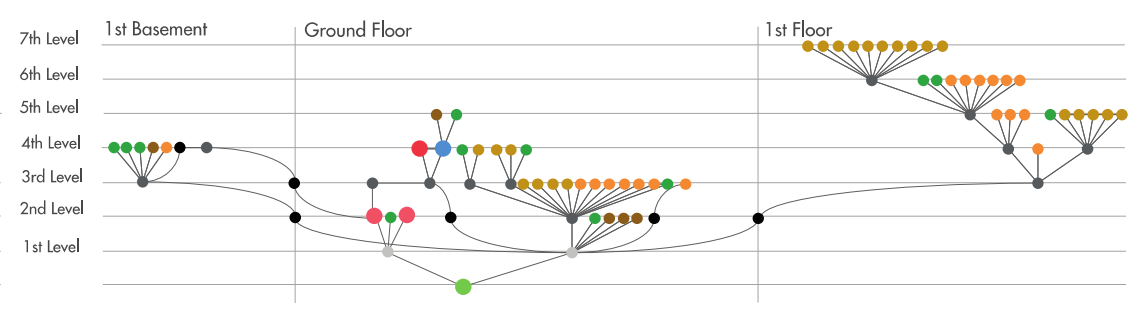

Caption

- Learning Spaces — Research Spaces - Administrative Spaces - Technical Areas • Circulation Areas • Accesses • Areas with exterior access

- Auditorium L Library European Information Centre - Europe Direct Café Outdoor

Figure 6. Justified graph of the Agrarian and Health Schools, Polytechnic Institutes of Beja and Bragança. 
The first building, that corresponds to the areas identified on the left-hand side of the graph, presents a very clear structure, grounded on the circulation areas, from where it is possible to reach most spaces within the building. It presents a maximum 6-step distance range from the exterior, and areas are distributed similarly among different deepness ranges, apart from the administrative areas, clustered on a highly accessible area. The second building, despite having a different circulation structure, with less clear distribution areas, is one level shallower in terms of global structure than the previous and shows less dispersion of functions. All spaces used by the academic community are located within a 4-step distance reach, and the building presents a maximum 5-step distance range from the exterior, but this maximum distance spaces consist only of technical areas. As a consequence, the perception of the users is of a shallower building.

In terms of the functional area likely to be used by the external community, the café is located at the third level of deepness on the ground floor of the first building and the auditorium is at the fourth level of deepness on the first floor of the second building.

The Agrarian School of Bragança stands out for the variation of heights in the terrain and the fact that all floors have outside access. This fact is highly visible in the graph, which presents a structure strongly grounded on the spaces that have access to the exterior, rather than on inner circulation and distribution areas. The graph structure is overall less deep than in the Agrarian School of Beja, although also less clear and seemingly less organized. The functional distribution, however, is similar, with a balanced distribution of spaces among the 5-step distance deepness levels.

There are three auditoriums directly accessible from the entrance, at the second level of accessibility. The café and the library are on the same floor at the second and third accessibility levels respectively. This school houses the European Information Centre of Bragança-Europe Direct at the second accessibility level.

Similarly, to what was verified in the case of the Agrarian School of Beja, the Health School also presents a very hierarchical structure, with a very clear demarcation of functional areas. The school is distributed along two wards, and most spaces are grounded on circulation spaces which are parallel to the main façade. The whole building presents a maximum of 5-step distance range, with a shallower structure than the agrarian school. This maximum deepness level is where all the research areas and laboratories are located. The public areas considered - the café and the auditorium are both located at the entrance floor, within a 4-step distance range from it.

The Health School of Bragança presents a more complex structure, marked by height differences within the same floor, which creates a broader range of deep areas within floors, especially at the ground floor and basement levels. On the upper floor, the distribution of spaces is grounded on circulation spaces as it happens in the Health School of Beja, and similarly, the deepest spaces within the school are research areas and laboratories. Public areas, such as the café and auditorium are located at the main entrance floor, however do not occupy the shallower spaces (i.e., the easiest to reach). The library, on the other hand, is highly reachable, being accessed from within the building, as well as directly from the exterior.

\section{Results}

The analysis shows that the polytechnic institutions examined present low values of integration (closeness centrality) which means they have a low potential of becoming to-destinations within their hosting cities. This situation is balanced with the higher values of normalized angular choice (betweenness centrality), especially if considering solely the main entrance of the precinct as a reference, which demonstrate that in both cases, but more visibly in Beja, the Polytechnic Institutes have the potential to be used in through-movement travels throughout the city (Figure 7). Despite the fact that this feature enhances the precincts visibility, the Polytechnic Institutions scoped in this paper are still limited by their spatial configuration in terms of promoting serendipitous encounters when it comes to academic-external community relationships, since spatial configuration plays key role in enabling and promoting encounter and social interaction [30,32,48]. 


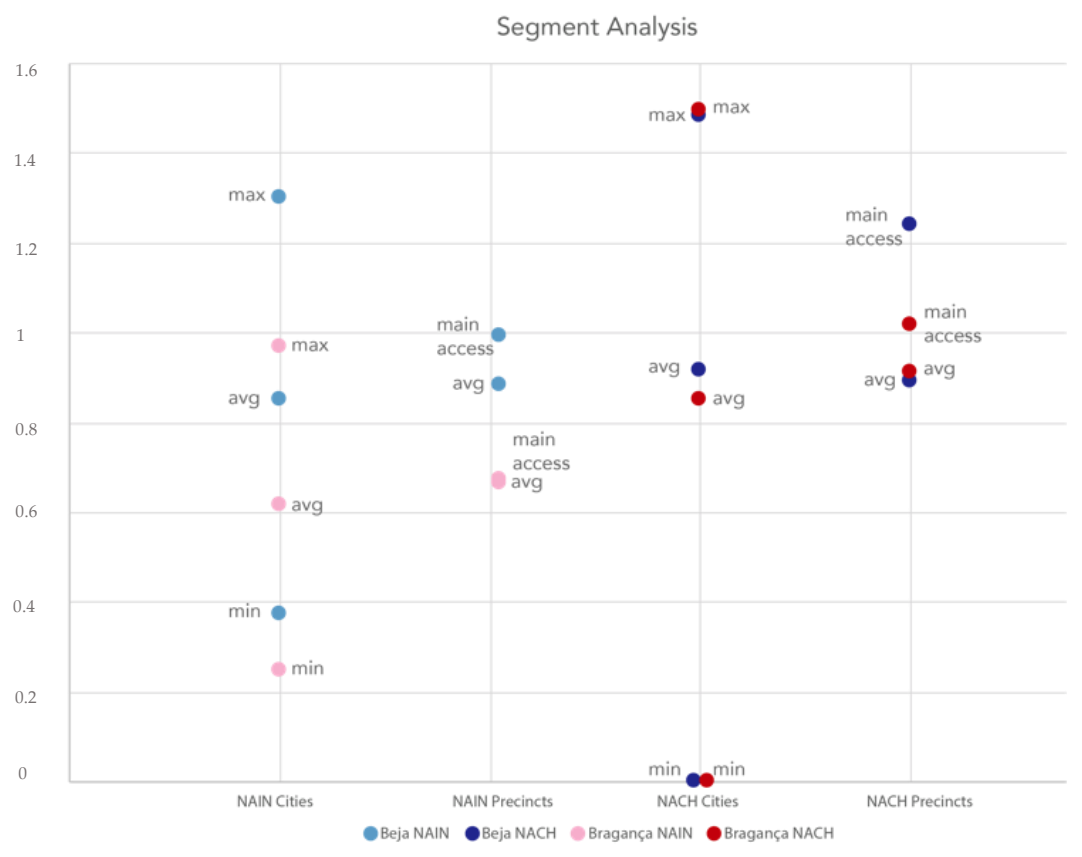

Figure 7. Segment analysis summary.

Comparing both schools, it is perceptible that the Agrarian School of Beja has a clear and hierarchic structure, that emphasizes learning spaces and offices. On the other hand, the Agrarian School of Bragança has a more organic structure, from which it is not easy to identify a circulation pattern, but enables almost immediate accessibility to most functions, and concentrates all functional areas that can have a shared use at a very shallow level from the entrance (Figure 8).
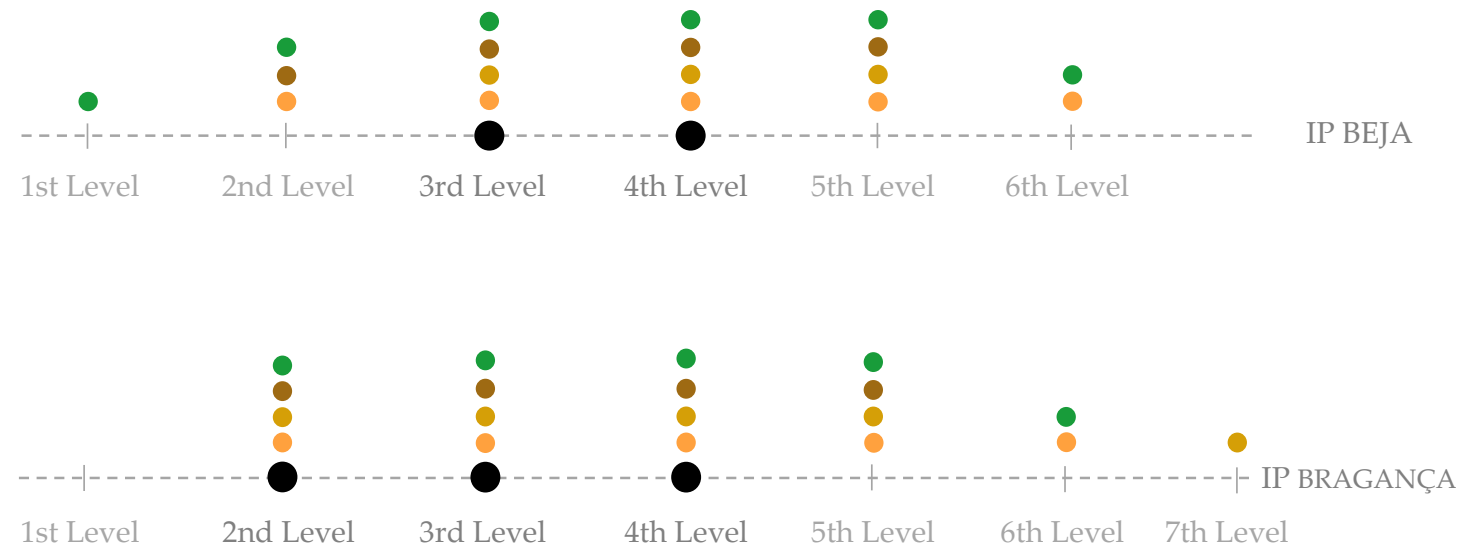

Spaces with the potential to be used by the exterior community

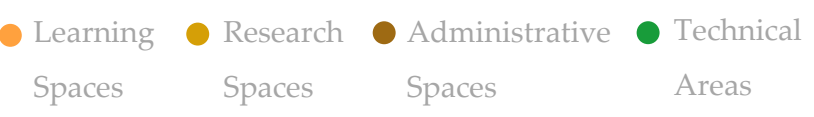

Figure 8. Functional analysis summary.

It is noteworthy that the lowest values of centrality showed in Bragança when analyzing the precinct at the macro-scale of the city are reversed at the micro-scale, and it becomes visible that the most public areas, and the ones with more potential to be used by exterior users, are easier to reach than in Beja, and all placed on the ground floor.

Maximum space deepness observed in the analyzed cases reaches between 5 and 7 distance steps, while the spaces with the potential to be used by the exterior community are mostly located 
between 2 and 4 steps of distance, making them easier to reach and, consequently, more accessible to any user.

This analysis demonstrates that there seems to be no clear intention while designing polytechnic institutions to create public spaces within the precinct. However, their configuration is flexible enough to enable a more open character without major changes in the buildings.

\section{Discussion}

This analysis does not intend to cover all variables, but rather to focus on configuration at two scales: the city scale, and the building scale. This approach, while limited in terms of social context, provides accurate insight on movement potentials and the level of publicness experienced by the precincts. Other works have highlighted the impact of publicness and visibility [42,49] within urban systems as central for successful relationships between town and gown.

This work aims at providing a methodology for objective analysis of the location and structural organization of higher education precincts. While space syntax has demonstrated to be very effective in this analysis, some other methods could be followed in order to provide complementary information, such as in-loco observations with flow counts. Also, in order to access the perceived publicness degree of each space, post-occupancy evaluation techniques such as walkthroughs and users' mental maps would allow for confirming the data obtained from the syntactic analysis. Nevertheless, this methodology allows for the creation of a database of higher education precincts, for its replicability and for the possibility of applying it to different contexts, despite the different social characteristics of each one.

The obtained results present some promising insights in correlating the necessary level of seclusion desired by these institutions and high visibility at the city scale, making them institutions that belong to the public realm, even if the civic community does not use their facilities. Further developments include an assessment of the impact of the perceived level of visibility that can be correlated with the syntactic analysis, as well as the application of the methodology at a broader scale.

\section{Conclusions}

This paper highlights the pertinence of vocational oriented knowledge infrastructure, in the context of the binary higher education system currently present in Portugal. It argues that the physical location of polytechnic institutes is a key factor in promoting their integration, which is a vital aspect due to their local and regional impact. Since “(...) the learning campus is one that maximizes the probability of chance encounters, and encourages lingering once an encounter-whether by chance or by plan-takes place" [50] (p. 39) efforts should be put into creating the opportunities for serendipitous encounters for the academic and the civic community, at both the city scale and the precinct scale.

This paper aims at providing a methodology for general characterization of regionally oriented higher education institutions in terms of their location within urban systems, but also as far as the spatial organization of the institutions is concerned. In this sense, its conclusions rely mostly on the adequacy of the assessment tool rather than on the conclusions of the analysis, that comprehends just two case studies and, for that reason, does not allow for any extrapolation of the results. However, despite its small sample, this analysis raises the question of spatial integration both at the city and the institution scales, and demonstrates that these should be complementary, and jointly thought of during the design process leading to the implementation of a higher education precinct.

The macro-scale analysis creates a framework for analyzing both the city's structure and the location of the higher education institutions in this structure, anticipating engagement levels and movement potentials. It allows to inform the design process at several scales, from the urban planning process of the precincts, to each building. It also provides the understanding on what features can be significant in view of the movement potentials achieved in the precinct.

The micro-scale analysis allows to understand the relative importance given to each space within the precinct. It informs about the general configuration of each building, accessibility levels, easiness 
in reach each individual space, and circulation systems. It also allows to infer on the character of each institution, through the closeness or openness of its spaces.

It is a highly replicable methodology, that is adequate both for the assessment at a larger scale of institutions of the same type, but also can be applied to different types of institutions whose morphology corresponds to transitional scales (as higher education precincts, whose scale of impact is located between urban scale and building scale, behaving as "cities in microcosm" [51]).

This methodology has demonstrated positive results, however still needs to be tested on a broader selection of cases. Future developments will include its vaster application in order to obtain clearer results on the integration features of higher education institutions, specifically considering the connections between the two scales of analysis, both in polytechnic and university cases.

Author Contributions: Conceptualization, T.H. and L.C.d.S.; Methodology, T.H.; Software, M.T.; Validation, M.T., L.C.d.S. and T.H.; Formal Analysis, M.T.; Investigation, M.T., L.C.d.S. and T.H.; Resources, T.H.; Data Curation, T.H. and L.C.d.S.; Writing-Original Draft Preparation, L.C.d.S. and M.T.; Writing-Review \& Editing, T.H. and L.C.d.S.; Visualization, M.T.; Supervision, L.C.d.S. and T.H.; Project Administration, T.H.; Funding Acquisition, T.H.

Funding: This research received no external funding.

Conflicts of Interest: The authors declare no conflict of interest.

\section{References}

1. Trow, M. From Mass Higher Education to Universal Access: The American Advantage; Kluwer Academic Publishers: Berkeley, CA, USA, 2000.

2. Da Fonseca, M.P. The Student Estate. In Higher Education in Portugal 1974-2009: A Nation, A Generation; Springer: Dordrecht, The Netherlands, 2012; pp. 383-415.

3. PACEC; CBR. The Higher Education Knowledge Exchange System in the United States; PACEC: Cambridge, UK, 2010.

4. Allen, T.J. Managing the Flow of Technology; The MIT Press: Cambridge, MA, USA; London, UK, 1977.

5. Greene, M.; Penn, A. Socio-Spatial Analysis of Four University Campuses. In Proceedings of the Space Syntax First International Symposium, London, UK, 16-18 April 1997; Available online: http:/ / discovery. ucl.ac.uk/1754/ (accessed on 27 August 2018).

6. Sailer, K.; Penn, A. Spatiality and transpatiality in workplace environments. In Proceedings of the 7th International Space Syntax Symposium, Stockholm, Sweden, 8-11 June 2009; Koch, D., Marcus, L., Steen, J., Eds.; KTH: Stockholm, Sweden, 2009; pp. 1-11.

7. Schwander, C.; Kohlert, C.; Aras, R. CAMPUSANALYST. Towards a spatial benchmarking system for university campuses. A case study of the university Hamm-Lippstadt. In Proceedings of the 8th International Space Syntax Symposium, Santiago de Chile, Chile, 3-6 January 2012; Greene, M., Reyes, J., Castro, A., Eds.; PUC: Santiago de Chile, Chile, 2012; pp. 1-18.

8. Cannas da Silva, L.; Heitor, T.; Campos Calvo-Sotelo, P. How exclusive do we want to be? exploring university morphology in the contemporary urban realm. In Proceedings of the 11th Space Syntax Symposium, Lisbon, Portugal, 3-7 July 2017; Heitor, T., Ed.; Instituto Superior Técnico: Lisbon, Portugal, 2017.

9. Da Fonseca, M.P.; Encarnação, S. O Sistema de Ensino Superior em Mapas e Números; A3ES: Lisboa, Portugal, 2012.

10. Rothblatt, S. Prolegomena to an Inquiry into the Campus Invisible. In Towards a Cartography of Higher Education Policy Change. A Festschrift in Honour of Guy Neave; CHEPS: Enschede, The Netherlands, 2007; pp. $45-52$.

11. Fonseca, M. The Student Estate. In Portugal 1974-2009. A Nation, a Generation; Neave, G., Amaral, A., Eds.; Springer: Dordrecht, The Netherlands, 2011; pp. 383-416.

12. Scott, P. Massification, Internationalization and Globalization. Available online: http://www.scirp. org/(S(351jmbntvnsjt1aadkposzje))/reference/ReferencesPapers.aspx?ReferenceID=1536433 (accessed on 27 August 2018).

13. Da Fonseca, M.P.; Encarnação, S. O Sistema de Ensino Superior em Portugal: Análises Sectoriais; A3ES: Lisboa, Portugal, 2013.

14. Fonseca, M.P.; Encarnação, S. Sistema de Ensino Superior em Portugal. Perfis Institucionais: Universidades Públicas; A3ES: Lisboa, Portugal, 2012. 
15. Fonseca, M.P.; Encarnação, S. Sistema de Ensino Superior em Portugal. Perfis Institucionais: Institutos Politécnicos Públicos. Available online: http://www.a3es.pt/sites/default/files/R4_MAPAS\&Nos_0.pdf (accessed on 27 August 2018).

16. OECD. Reviews of National Policies for Education: Tertiary Education in Portugal; OECD Publishing: Paris, France, 2007.

17. OECD. OECD Review of the Tertiary Education, Research and Innovation System in Portugal (2016-2017); OECD Publishing: Lisbon, Portugal, 2018.

18. Assembleia da República. Lei n.o 62/2007 de 10 de setembro. In Regime Jurídico das Instituições de Ensino Superior; Diário da República-I Série: Lisbon Portugal, 2007.

19. DGEEC. Estatísticas da Educação 2015/16; DGEEC: Lisbon, Portugal, 2017.

20. Cannas da Silva, L. Campus as a City-City as a Campus. A Morphological Approach to University Precincts in Urban Dynamics; Universidade de Lisboa: Lisbon, Portugal, 2017.

21. Toscano, M. Rede de Ensino Superior Politécnico Público em Portugal Distribuição Espacial e Caracterização Morfo-Tipológica; University of Lisbon: Lisbon, Portugal, 2018.

22. Knight, R. Knowledge-Based Development: Policy and Planning Implications for Cities, Urban Studies. SAGE J. 1995. [CrossRef]

23. Den Heijer, A. Managing the University Campus_Information to Support Real Estate Decisions; Eburon Academic Publishers: Delft, The Netherlands, 2011.

24. Indovina, F. Sinergi Tra Communità e Università. In Archivio di Studi Urbani e Regionali; 1997 28/29(60/61); Franco Angeli Edizioni: Milan/Rome, Italy.

25. Corneil, J.; Parsons, P. The Contribution of Campus Design to the Knowledge Society: An International Perspective. In Campus and the City-Urban Design for the Knowledge Society; Christiaanse, K., Hoeger, K., Eds.; Gta Verlag/ETH Zurich: Zurich, Switzerland, 2007.

26. RIBA. Building Futures. In Growing by Degrees: Universities in the Future of Urban Development; RIBA: London, UK, 2009.

27. Witty, A. Encouraging a British Invention Revolution: Sir Andrew Witty's Review of Universities and Growth. London, 2013. Available online: https://www.gov.uk/government/consultations/universitiesand-growth-the-witty-review-call-for-evidence (accessed on 7 November 2017).

28. Van Winden, W. Knowledge and the european city. Tijdschr. Voor Econ. Soc. Geogr. 2010, 101, 100-106. [CrossRef]

29. Fouchier, V. Économie de la connaissance et aménagement universitaire dans les métropoles du monde. In Universités et Enjeux Territoriaux une Compairaison Internationale de L'économie de la Conaissance; Ingallina, P., Ed.; Presses Universitaires du Septentrion: Villeneuve d'Ascq, France, 2012; p. 320.

30. Hillier, B.; Hanson, J. The Social Logic of Space; Cambridge University Press: Cambridge, UK, 1984.

31. Hillier, B.; Hanson, J.; Peponis, J. What do we mean by building function? In Designing for Building Utilisation; Powell, J.A., Cooper, I., Lera, S., Eds.; E \& F.N. Spon: Portshmouth, UK, 1984; Volume 5, pp. 61-72.

32. Hillier, B.; Burdett, R.; Peponis, J.; Penn, A. Creating Life: Or, Does Architecture Determine Anything? Arch. Comport. Arch. Behav. 1987, 3, 233-250.

33. Al-Sayed, K.; Turner, A.; Hillier, B.; Iida, S.; Penn, A. Space Syntax Methodology, 2nd ed.; UCL: London, UK, 2014.

34. Hillier, B. Space Is the Machine; Press Syndicate of the University of Cambridge: Cambridge, UK, 1996.

35. Heitor, T.V.; Pinelo Silva, J. A Sintaxe Espacial e o Ambiente Construído-Análise Morfológica'. In O Estudo da Forma Urbana em Portugal; Oliveira, V., Marat-Mendes, T., Pinho, P., Eds.; Universidade do Porto: Porto, Portugal, 2015; pp. 147-190.

36. Peponis, J. The Space Syntax of Intelligible Communities. In Community Wayfinding: Pathways to Understanding; Hunter, R.H., Anderson, L.A., Belza, B.L., Eds.; Springer: Berlin, Germany, 2016; pp. 35-60.

37. Hillier, B.; Iida, S. Network and Psychological Effects in Urban Movement. In Spatial Information Theory; Cohn, A.G., Mark, D.M., Eds.; Springer: Berlin/Heidelberg, Germany, 2005; pp. 475-490.

38. Turner, A. Depthmap; University College London: London, UK, 2004.

39. Turner, A. Angular Analysis: A method for the Quantification of Space; Working Paper Series 23; CASA: London, UK, 2000; Available online: http://discovery.ucl.ac.uk/1368/1/paper23.pdf (accessed on 20 December 2017).

40. Turner, A. Angular Analysis. In Proceedings of the Third International Space Syntax Symposium, Atlanta, Georgia, 7-11 May 2001; pp. 30.1-30.11. 
41. Hillier, B.; Yang, T.; Turner, A. Normalising least angle choice in Depthmap and it opens up new perspectives on the global and local analysis of city space. J. Space Syntax 2012, 3, 155-193.

42. Adhya, A. Evaluating the Campus-Downtown Relationship the Spatial Configuration of Four College Towns in Small Metropolitan Regions in the United States. In Proceedings of the 7th International Space Syntax Symposium, Stockholm, Sweden, 8-11 June 2009; Koch, D., Marcus, L., Steen, J., Eds.; KTH: Stockholm, Sweden, 2009; pp. 1-19.

43. Cannas da Silva, L.; Heitor, T. University Precincts in Lisbon Metropolitan Area: A morphological description. In PNUM 2012: Urban Morphology in Portuguese Speaking Countries; Marat-Mendes, T., Ed.; ISCTE-Instituto Universitário de Lisboa: Lisbon, Portugal, 2012; pp. 1284-1296.

44. Bacharel Carreira, M.; Heitor, T.V.; Alegre, A. School-place as a Collective Urban Entity. The case study of Lisbon. In Proceedings of the 11th Space Syntax Symposium, Lisbon, Portugal, 3-7 July 2017; Heitor, T.V., Alegre, A., Eds.; Instituto Superior Técnico: Lisbon, Portugal, 2017.

45. Coutinho, B.; Santos, R.F.; Fernandes, A. Space syntax as a tool for an open museum practice: The case of MUDE Museum. In Proceedings of the 11th International Space Syntax Symposium, Lisbon, Portugal, 3-7 July 2017; pp. 8.1-8.15.

46. Benneworth, P.; Charles, D.; Madanipour, A. Building Localised Interactions between Universities and Cities through University Spatial Development. Eur. Plan. Stud. 2010, 18, 1611-1629. [CrossRef]

47. Hillier, B. Space Syntax as a Theory as well as a Method. In Proceedings of the 21st International Seminar on Urban Form, Porto, Portugal, 3 July 2014; Available online: http:/ /isuf2014.fe.up.pt/ (accessed on 16 October 2017).

48. Hillier, B.; Penn, A. Visible Colleges: Structure and Randomness in the Place of Discovery. Sci. Context 1991, 4, 23-49. [CrossRef]

49. Adhya, A. The Public Realm as a Place of Everyday Urbanism: Learning from Four College Towns. Ph.D. Thesis, University of Michigan, Ann Arbor, MI, USA, 2008.

50. Kenney, D.R.; Dummont, R.; Kenney, G. Mission and Place. Strengthening Learning and Community through Campus Design; Praeger Publishers: Westport, CT, USA, 2005.

51. Turner, P.V. Campus-An American Planning Tradition, the Architectural History Foundation; MIT Press: Cambridge, MA, USA, 1984.

(C) 2018 by the authors. Licensee MDPI, Basel, Switzerland. This article is an open access article distributed under the terms and conditions of the Creative Commons Attribution (CC BY) license (http:/ / creativecommons.org/licenses/by/4.0/). 